\title{
Anomalous Moisture Transport and Oceanic Evaporation during a Torrential Rainfall Event over Western Japan in Early July 2018
}

\author{
Shion Sekizawa ${ }^{1}$, Takafumi Miyasaka ${ }^{1,2,3}$, Hisashi Nakamura ${ }^{1}$, Akihiko Shimpo ${ }^{4}$, \\ Kazuto Takemura, ${ }^{4,5}$, and Shuhei Maeda ${ }^{3}$ \\ ${ }^{1}$ Research Center for Advanced Science and Technology, the University of Tokyo, Tokyo, Japan \\ ${ }^{2} J a p a n$ Meteorological Business Support Center, Tsukuba, Japan \\ ${ }^{3}$ Meteorological Research Institute, Tsukuba, Japan \\ ${ }^{4}$ Climate Prediction Division, Japan Meteorological Agency, Tokyo, Japan \\ ${ }^{5}$ Graduate School of Science, Kyoto University, Kyoto, Japan
}

\begin{abstract}
During a torrential rainfall event in early July 2018, profound enhancement of moisture influx from the south and its convergence occurred over western Japan, which is investigated in this study on the basis of objective analysis and forecast data from the Japan Meteorological Agency Meso-Scale Model. The heavy rainfall over western Japan is found to accompany enhanced oceanic evaporation extensively around Japan, especially around the Kuroshio and entirely over the Sea of Japan. Linear decompositions of the anomalous moisture flux and surface latent heat flux anomalies applied to the high-resolution data reveal that the intensified speed of the low-level southerlies was the primary factor for the pronounced enhancement of both the moisture transport into the heavy rainfall region, especially in its western portion, and evaporation around the Kuroshio into the southerlies. An additional contribution is found from positive sea-surface temperature anomalies to the enhanced southerly moisture inflow into the eastern portion of the rainfall region. These findings have been confirmed through a backward trajectory analysis, which suggests that anomalous moisture supply to air parcels into the rainfall region primarily through the enhanced wind-forced evaporation roughly corresponds to about $10 \%$ of the precipitable water anomaly over western Japan.
\end{abstract}

(Citation: Sekizawa, S., T. Miyasaka, H. Nakamura, A. Shimpo, K. Takemura, and S. Maeda, 2019: Anomalous moisture transport and oceanic evaporation during a torrential rainfall event over western Japan in early July 2018. SOLA, 15A, 25-30, doi: 10.2151/sola.15A-005.)

\section{Introduction}

Western Japan and the adjacent Tokai region (geographical locations of the regions referred to in this paper are summarized in Fig. S1) experienced torrential rainfall in early July 2018, which caused severe floods and landslides (Tsuguti et al. 2019). As described by Shimpo et al. (2019), this extreme event was associated with pronounced enhancement of poleward moisture flux and its convergence over western Japan.

Some recent studies have pointed out an essential role of sea-surface temperature (SST) over the surrounding oceans in extreme rainfall events through the anomalous heat and moisture supply to airflows. Manda et al. (2014) have shown that rapid seasonal warming of the East China Sea (ECS) from early to midsummer influences the seasonality of torrential rainfall events over western Kyushu of Japan and the future ECS warming will likely increase rainfall amount substantially in such events. Fujibe (2015) has found long-term increasing trends in both extreme precipitation observed over Japan and SST over the surrounding

Corresponding author: Shion Sekizawa, RCAST, University of Tokyo, 4-6-1 Komaba, Meguro-ku, Tokyo, Japan. E-mail: shion@atmos.rcast. u-tokyo.ac.jp. seas. Thus, it is worthwhile to investigate the condition of the surrounding seas behind the torrential rainfall event in July 2018.

Anomalous latent heat flux from the ocean can be driven not only by SST anomaly but also by anomalies in surface wind speed and air humidity. In this study, we investigate anomalous oceanic evaporation and its contribution to moisture transport during this extreme rainfall event over western Japan, based on highresolution data from the Japan Meteorological Agency (JMA) Meso-Scale Model (MSM). We first confirm that the significant moisture transport toward western Japan was associated with the torrential rainfall, as described in detail by Takemura et al. (2019; submitted) based on a global atmospheric reanalysis (JRA-55; Kobayashi et al. 2015). Through a linear decomposition analysis for anomalous surface latent heat flux (LHF), we attempt to determine factors for the anomalous oceanic evaporation. We also perform a decomposition of horizontal moisture flux within the atmospheric mixed layer and a backward trajectory analysis to elucidate the relationship between anomalous oceanic evaporation and moisture transport.

\section{Data and analysis methods}

\subsection{Data}

For wind velocity, temperature, humidity, rainfall and SST fields, we used objective analysis and forecast data from the JMA MSM (e.g., JMA 2017). This is an operational regional model with a horizontal resolution of $0.0625^{\circ} \times 0.05^{\circ}$ (about $5.5 \mathrm{~km}$ ), which is approximately 10 times higher than that of JRA-55. As its lower boundary condition, MSM uses the JMA Merged satellite and in-situ data Global Daily SST (MGDSST; Kurihara et al. 2006). Our analyses are based on 3-hourly MSM outputs for the variables at pressure levels (analysis except vertical motion) and hourly outputs for those variables available on the surface. The latter consists of 3-hourly analysis and forecast from the latest initial time, although rainfall amount is anytime based on forecast. Climatological daily fields are defined as 15-day running mean of interannually averaged fields from 2006 to 2017. Although one may consider that 12 years may be too short for defining daily climatology, the climatological fields thus obtained are found to be consistent with their counterpart derived similarly from the JRA-55 based on both the same 12-year period and 37-year period from 1981 to 2017. In this study, we focus on the peak period of the event from 0900 Japan Standard Time (JST) 5 July to 0900 JST 7 July, when the Baiu front stagnated and extreme precipitation was observed over western Japan. Our analyses are based on 48-hour mean fields for the peak period, except the backward trajectory analysis.

\subsection{Linear decomposition of surface latent heat flux and hori- zontal moisture flux}

Since the MSM analysis provides no surface LHF fields, they are estimated for our analyses over the ocean from the surface MSM data by using the COARE 3.0 bulk flux algorithm (Fairall 
et al. 2003). To seek for the factors behind the enhanced oceanic evaporation associated with the torrential rainfall event, we perform a linear decomposition of the local LHF anomaly based on the bulk formula

$$
Q=\rho_{a} L C_{E} W\left\{q_{s}\left(T_{S}\right)-q_{q}\right\},
$$

where $Q$ and $W$ denote the turbulent LHF and 10-m scalar wind speed, while $q_{s}$ and $q_{a}$ are saturation specific humidity at SST $\left(T_{S}\right)$ and $1.5-\mathrm{m}$ specific humidity, respectively. $\rho_{a}, L$ and $C_{E}$ are air density, latent heat of vaporization and the bulk coefficient, respectively. Following Tanimoto et al. (2003), we can decompose the bulk formula as

$$
\begin{aligned}
Q^{\prime} & =Q-\bar{Q} \\
& =\rho_{a} L C_{E}\left\{W^{\prime}\left(\bar{q}_{s}-\bar{q}_{a}\right)+\bar{W} q_{s}^{\prime}\left(T_{S}^{\prime}\right)-\bar{W} q_{s}^{\prime}+W^{\prime}\left(q_{s}^{\prime}-q_{a}^{\prime}\right)\right\},
\end{aligned}
$$

where overbars and primes denote the climatologies and anomalies, respectively. We can derive $\rho_{a} L C_{E}$ from the local climatological fields as $\bar{Q} / \bar{W}\left(\bar{q}_{s}-\bar{q}_{a}\right)$. Thus, $\rho_{a} L C_{E}$ has spatial distribution and seasonality but is interannually constant. The first through third terms on the RHS represent linear contributions to the anomalous LHF from local anomalies in surface wind speed, SST and humidity, respectively, whereas the fourth term indicates the corresponding contribution from nonlinear effects of these anomalies. Note that $q_{s}^{\prime}$ is expressed in terms of $T_{S}^{\prime}$ via the Clausius-Clapeyron equation.

Likewise, we also apply a similar decomposition to the moisture flux anomaly as

$$
(q v)^{\prime}=\bar{q} v^{\prime}+q^{\prime} \bar{v}+q^{\prime} v^{\prime}
$$

where $q$ and $v$ denote specific humidity and horizontal wind velocity, respectively. The first and second terms on the RHS represent linear contributions to the anomalous moisture flux from anomalies in wind and humidity, respectively, whereas nonlinear contribution is included in the third term. In the following, we show the horizontal moisture flux vertically integrated within the atmospheric mixed layer from the surface to $925 \mathrm{hPa}$, where potential temperature tended to be vertically uniform and the air was almost saturated during the peak period (Fig. S2).

\subsection{Backward trajectory analysis of moist air parcels}

For a quantitative discussion, we assess the contribution from the anomalous evaporation to moisture transport into the heavy rainfall region based on a backward trajectory analysis, where tracing of air parcels from grid points at $500 \mathrm{~m}$ above the surface was started every three hours from 0900 JST 5 July to 0600 JST 7 July. Those air parcels were then traced backward at 5-minute intervals by the Eulerian method in following the MSM threedimensional winds. We assume that air parcels are following the grid-scale winds in the MSM data, and therefore the direct effect by sub-grid-scale motions is not included.

\section{Results}

\subsection{Overall feature of moisture transport and surface evaporation}

In the peak period of the event, the stationary Baiu front accompanied a distinct precipitation band over western Japan that extended eastward to Tokai region (Fig. 1a). As evident from Fig. 1, low-level moisture inflows to the rainband consisted of two major branches: one is associated with strong southwesterlies over the southern ECS along the Okinawa Islands that originated from the monsoon westerlies, and the other originated from the Trades along the southern flank of the Bonin High (or North Pacific Subtropical High), turning northward to the south of Japan. The two branches merged together just to the south of the rainband. Takemura et al. (2019) have shown that the convergence of the southerly moisture flux within western Japan during the peak period was the strongest in the last 60 years. We emphasize that the northward moisture inflows traveled over the warm Kuroshio, along which the evaporation maximizes climatologically (Fig. 1b). An additional moist airflow was associated with the strong northeasterlies entirely over the Sea of Japan to the south of the intensified Okhotsk High. Since this airflow was, however, overall parallel to the stationary Baiu front, it is not obvious to what extent this flux contributed to the heavy rainfall over western Japan.

Figure 1c illustrates anomalous surface LHF, and surface wind fields at $10 \mathrm{~m}$ elevation averaged over the peak period of the rain event. Positive LHF anomalies indicate enhanced moisture supply from the ocean to the atmosphere. The moisture inflows were crossing over the maritime regions around Japan, where surface evaporation was enhanced extensively. This suggests that the enhanced evaporation acted to increase the moisture transport toward the heavy rainfall region.

\subsection{Factors for the enhanced evaporation}

Before showing our results of the LHF decomposition for the peak period of the rainfall event, we first describe distributions of the individual anomalies included in the linearized bulk formula in Eq. (1). As shown in Fig. 2a, anomalous surface wind speed was overall positive, indicating intensification of surface winds almost entirely over the surrounding seas. Especially, the anomalous wind field features the three moist airstreams around the rainfall region, suggesting their prominence in the total wind field and anomalous LHF (Fig. 1c). SST was below normal around the Okinawa Islands and just east of the Kyushu Island, while SST (a) Rainfall \& Moisture transport

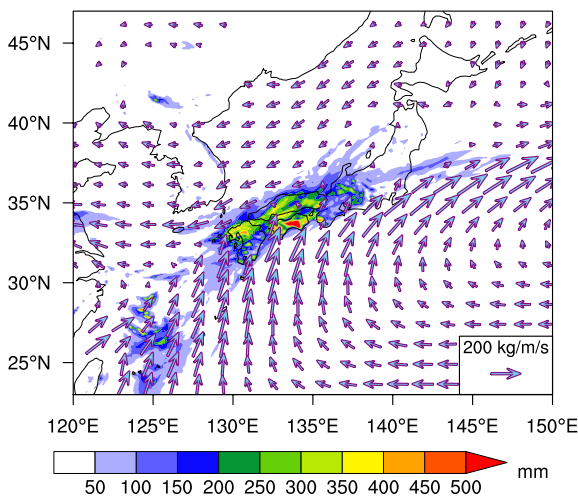

(b) Latent heat flux \& 10m wind (Clim.)

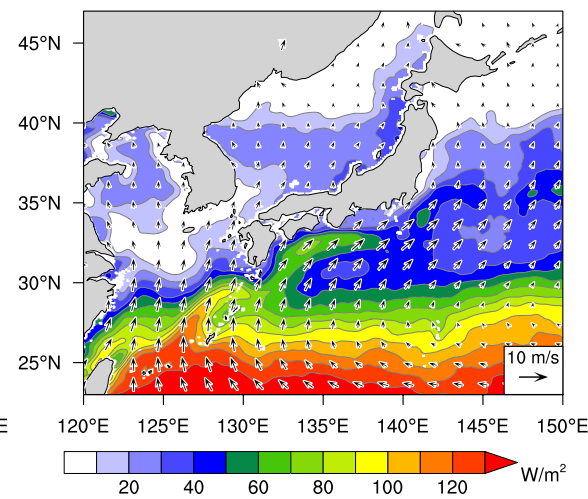

(c) Latent heat flux anomaly \& $10 \mathrm{~m}$ wind

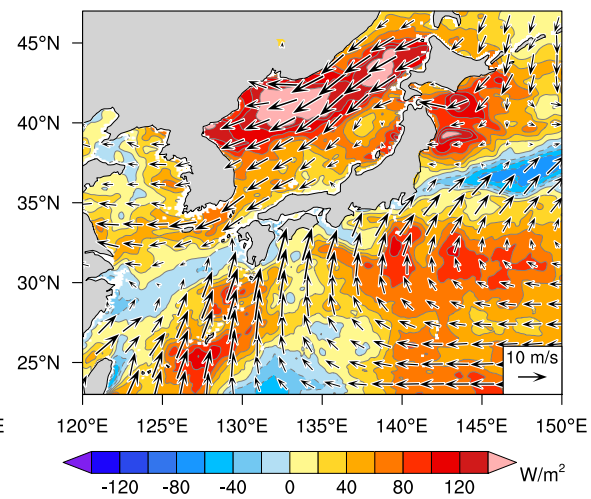

Fig. 1. (a) Total rainfall amount ( $\mathrm{mm}$, shading) and vertically integrated moisture flux from the surface to $925 \mathrm{hPa}$ level ( $\mathrm{kg} / \mathrm{m} / \mathrm{s}$, vectors), (b) climatologies in surface LHF (W/ $\mathrm{m}^{2}$, shading) and 10-m wind ( $\mathrm{m} / \mathrm{s}$, vectors), and (c) surface LHF anomaly (shading) and 10-m wind (not anomaly, vectors) during the peak period of the heavy rainfall event (48 hours from 0900 JST 5 July). 
(a) Surface wind speed anomaly

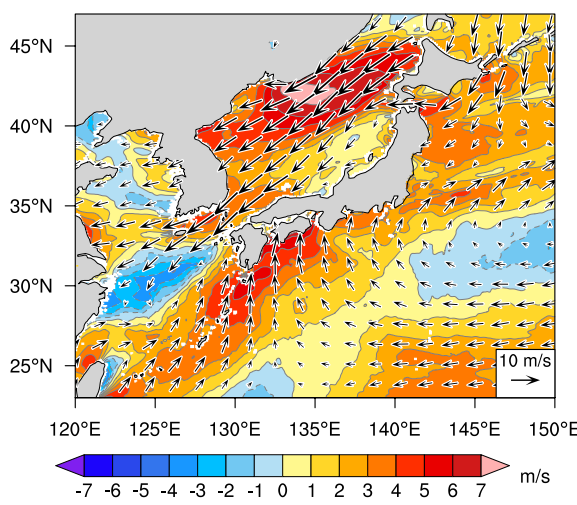

(b) SST anomaly

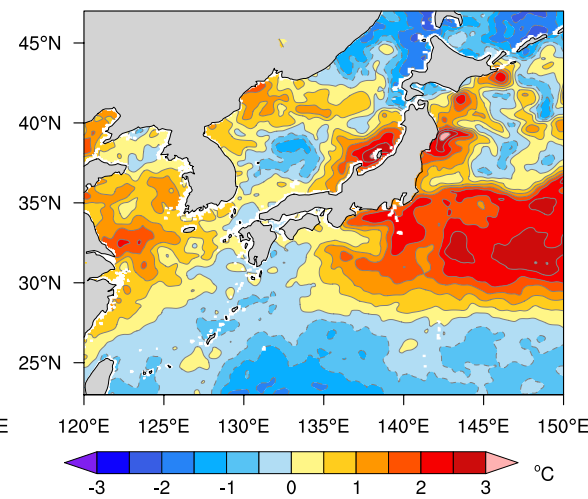

(c) $1.5 \mathrm{~m}$ specific humidity anomaly

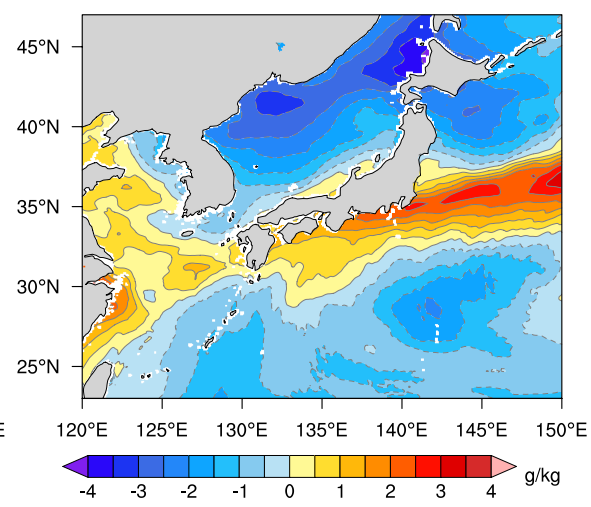

Fig. 2. Anomalies of (a) $10-\mathrm{m}$ wind $\left(\mathrm{m} / \mathrm{s}\right.$, vectors) and scalar wind speed ( $\mathrm{m} / \mathrm{s}$, shading), (b) SST $\left({ }^{\circ} \mathrm{C}\right)$ and $(\mathrm{c}) 1.5-\mathrm{m}$ specific humidity $(\mathrm{g} / \mathrm{kg})$, all averaged over the 48 -hour peak period of the rainfall event.

(a) Wind speed term

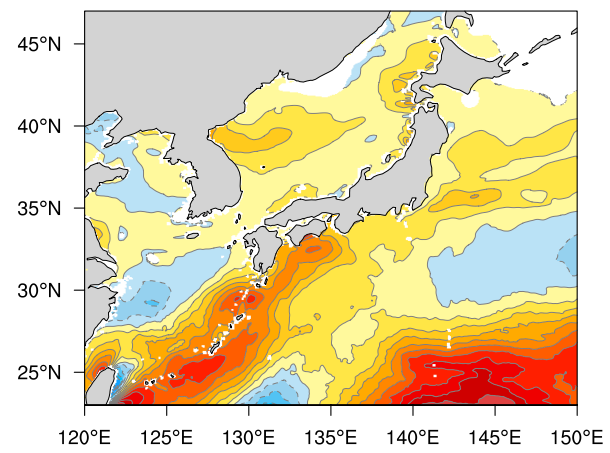

(c) Humidity term
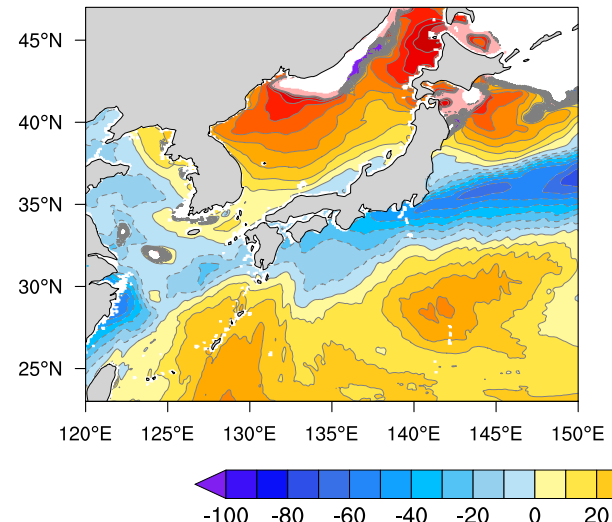

(b) SST term

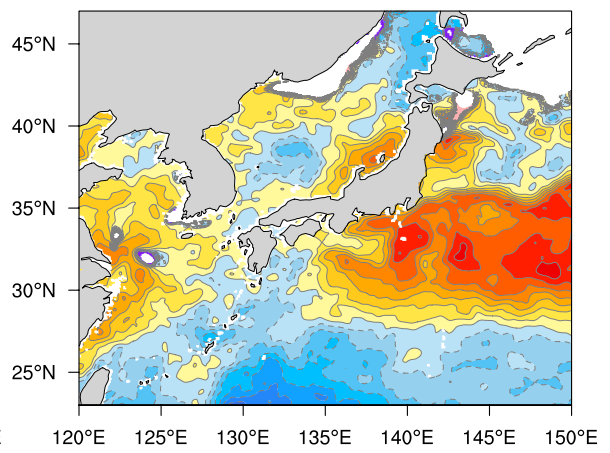

(d) Nonlinear term

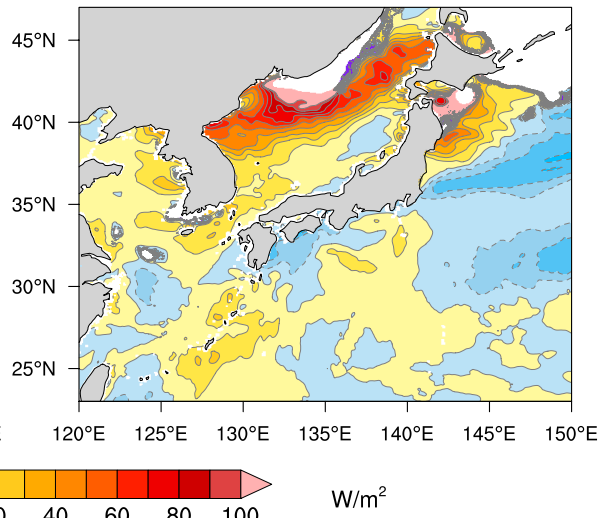

Fig. 3. Anomalies in surface LHF anomalies $\left(\mathrm{W} / \mathrm{m}^{2}\right)$ averaged over the 48-hour peak period of the rainfall event, due to (a) surface wind speed anomaly, (b) SST anomaly, (c) surface humidity anomaly and (d) nonlinearity between these anomalies. Based on the decomposition with the linearized bulk formula in Eq. (1). White color is applied where the denominator of the coefficient, $\bar{W}\left(\bar{q}_{s}-\bar{q}_{a}\right)$, is too small to estimate the LHF anomaly correctly.

was higher than normal in the Pacific south of central Japan poleward of $28^{\circ} \mathrm{N}$, despite under the enhanced surface southerlies and evaporation (Fig. 2b). As shown in Fig. 2c, anomalies in surface specific humidity were overall negative around Japan. An obvious exception is a belt of positive anomalies extending zonally to the south of the Baiu front. This band includes the region of extreme rainfall over western Japan and the Kuroshio to its south, where evaporation was enhanced.

Figure 3 exhibits the decomposed surface LHF anomalies, corresponding to the individual terms in Eq. (1). The sum of them is almost the same to the original LHF anomaly (Fig. S3), which confirms the validity of the decomposition. The contribution to the enhanced evaporation from the wind speed anomalies was dominant from the south of western Japan into the vicinity of the Okinawa Islands (Fig. 3a), while the contribution from the warm SST anomalies dominated over the wind speed contribution to the south of central Japan (Fig. 3b). Thus, the most likely factor for the enhanced moisture supply from the ocean to the southwesterly airstream into western Japan was its intensified speed, with an additional contribution from the positive SST anomalies to the enhanced moisture supply to the southerly airstream toward the eastern portion of the heavy rainfall region, including Tokai region. In the south of $30^{\circ} \mathrm{N}$, reduced surface humidity also positively contributed to the enhanced evaporation (Fig. 3c). The 
enhanced evaporation over the Sea of Japan was largely due to the outbreak of anomalous cool, dry air from the developed Okhotsk High and its nonlinear effect with the intensified northeasterlies (Figs. 3c and 3d).

\subsection{Factors for the enhanced moisture transport}

On the basis of Eq. (2), we conducted a decomposition of the anomalous moisture flux within the mixed layer shown in Fig. $4 \mathrm{a}$, in our attempt to find a linkage between the enhanced oceanic evaporation and intensified moisture transport into western Japan. As evident in Figs. $4 a$ and $4 b$, the anomalous moisture flux is accounted for mostly by the anomalous circulation acting on the climatological humidity distribution. Its convergence and divergence overall correspond to the rainband over western Japan (Fig. 1a) and the areas of enhanced oceanic evaporation (Fig. 1c), respectively. For a more quantitative argument, we examine northward moisture flux anomaly across $32.5^{\circ} \mathrm{N}$ within a longitudinal sector $\left[132-136^{\circ} \mathrm{E}\right]$ to the south of the Shikoku Island, as indicated with red lines in each panel of Fig. 4. All the three terms in Eq. (2) contribute positively to the enhancement of the northward moisture transport within the mixed layer. The contributions from the circulation anomaly, humidity anomaly and their nonlinear effects account for $86 \%, 4 \%$ and $10 \%$ of the total anomaly, respectively. The predominance of the circulation anomaly term indicates that the configuration of the lower-tropospheric circulation was the primary factor for the extreme moisture transport during the torrential rainfall event. The nonlinear contribution from the wind and humidity anomalies is smaller but by no means negligible. Its positive contribution just south of western Japan arises from the intensified southerlies in the more humid mixed layer over the warm Kuroshio, where the evaporation is enhanced. The anomalous moisture divergence due to this nonlinear effect is concentrated along the Kuroshio off western Japan (Fig. 4d), suggestive of local augmentation of the northward moisture transport into the heavy rainfall region by the evaporation from the Kuroshio.

\subsection{Backward trajectory analysis}

Figure 5a illustrates the trajectories of moist air parcels traced backward up to 24 hours after starting from six locations in western Japan during the heavy rainfall event. The trajectories suggest that almost all the air parcels have been transported primarily by the southerly airstreams (Fig. 1c) into the torrential rainfall region, implying that enhanced evaporation over the Sea of Japan is unlikely to act as an important moisture supply into the rainband (Figs. 1a and 1c). Figure 5b indicates evaporation anomalies accumulated along the 24-hour backward trajectories after averaged over all the trajectories traveling within the mixed layer (below $925 \mathrm{hPa}$ ) after starting from each of the grid points. The evaporation anomalies accumulated for the trajectories traveling within the mixed layer are positive for all the six starting locations $(0.7 \sim$ $1.9 \mathrm{~mm})$. The anomalies are comparable with column moisture anomaly within the mixed layer over the ocean just south of the Shikoku Island $(\sim 1.5 \mathrm{~mm}$; Fig. $6 \mathrm{a})$, accounting for $5 \sim 16 \%$ of precipitable water anomaly over western Japan $(\sim 12 \mathrm{~mm}$; within the domain indicated with the box in Fig. 6b). This implies that a considerable fraction of the column water vapor anomalies within the moist airstream into western Japan can be attributed to the enhanced oceanic evaporation over the south of Japan. Consistent with the Eulerian analysis for the anomalous evaporation (Fig. 3 ), the accumulated evaporation anomaly is primarily due to the intensified surface wind speed, which accounts for $72 \sim 94 \%$ of the total anomaly (Fig. 5c). By contrast, the corresponding contribution from the SST anomalies is almost zero or even negative for (a) Total anomaly

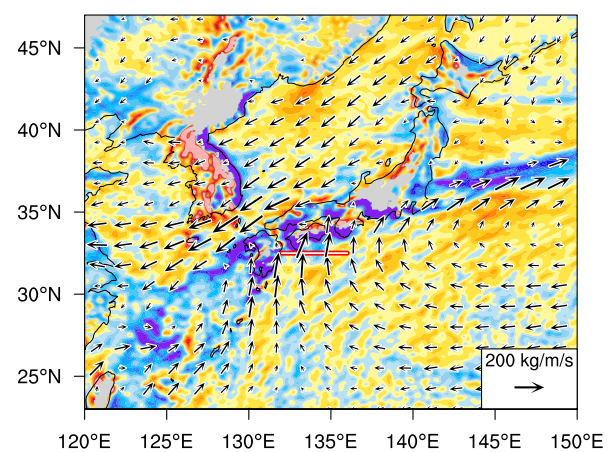

(c) Humidity anomaly term

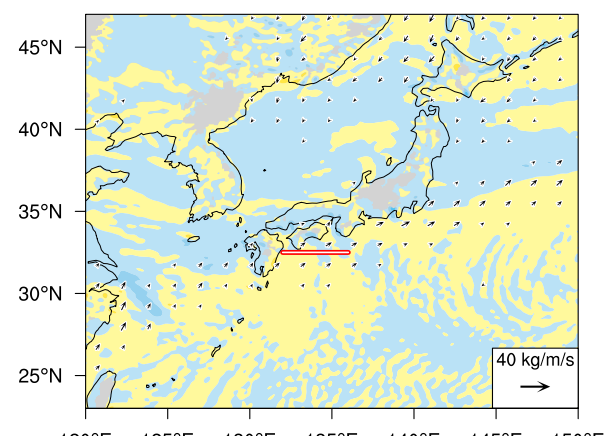

(b) Circulation anomaly term

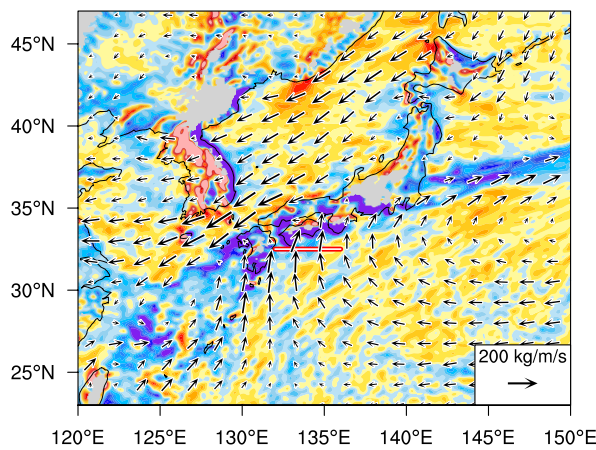

(d) Nonlinear term

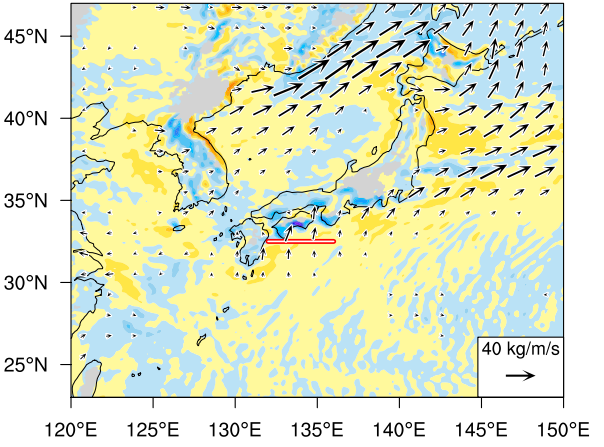

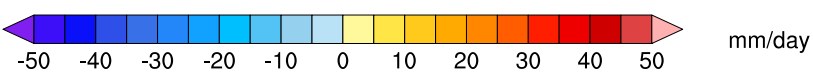

Fig. 4. (a) Moisture flux anomaly integrated vertically from the surface to $925 \mathrm{hPa}$ level (kg/m/s, vectors) and its divergence (mm/day; shading) as an average over the 48-hour peak period of the rainfall event, and contributions from (b) wind anomaly, (c) humidity anomaly and (d) nonlinearity between these anomalies, based on the decomposition in Eq. (2). Note that scales for vectors differ among the four panels, whereas color bar is common. In each panel, red line off the Shikoku Island indicates the longitudinal sector at $32.5^{\circ} \mathrm{N}$ used for calculating a contribution to the northward moisture flux anomaly from a particular anomaly. 
(a) 24-hour backward trajectories

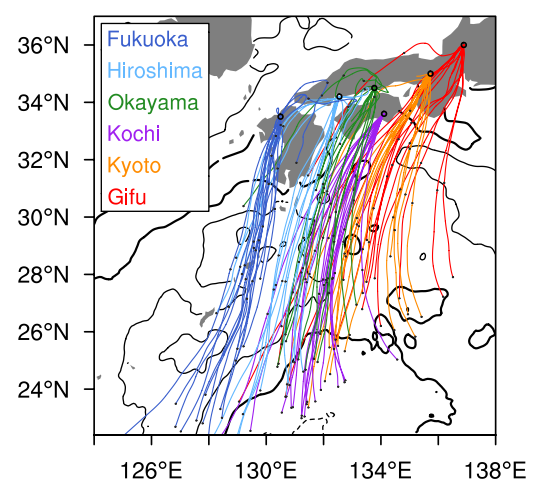

(c) Wind speed term

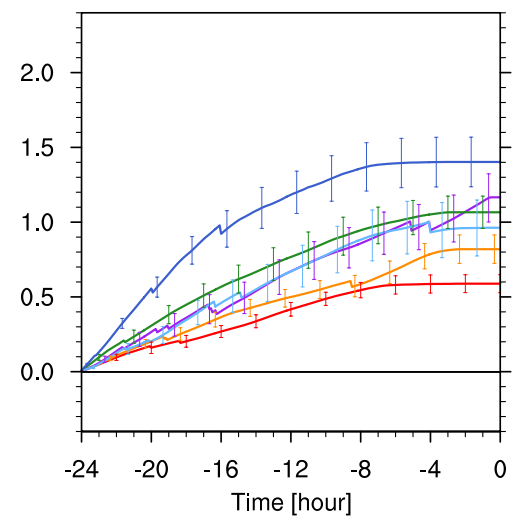

(b) Accumulated evaporation anom.

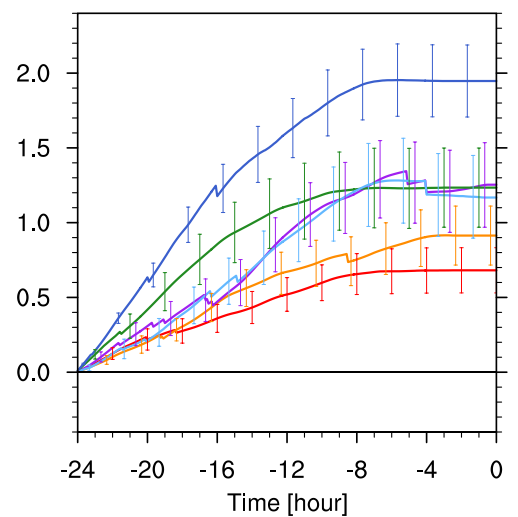

(d) SST term

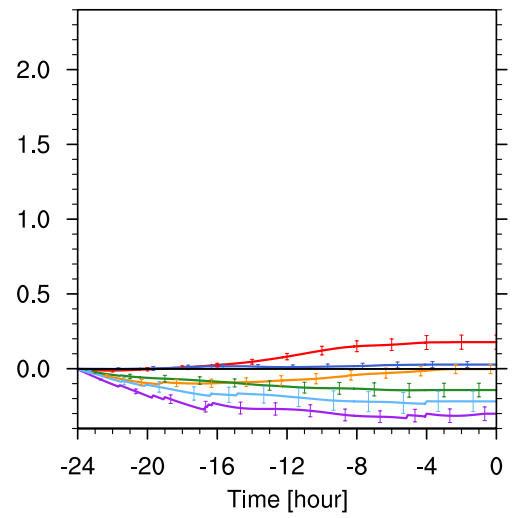

Fig. 5. (a) 24-hour backward trajectories originated from six grid points within the torrential rainfall area. Trajectories are superposed on LHF anomaly (contoured for $0, \pm 50, \pm 100 \mathrm{~W} / \mathrm{m}^{2}$, dashed for negative anomalies) averaged over the 48 -hour peak period of the rainfall event. (b) Accumulated anomalous evaporation (mm) along the trajectories, and the contributions from anomalies in (c) surface wind speed and (d) SST as estimated based on the linearized bulk formula in Eq. (1). Error bars denote standard error of the accumulated anomalous evaporation. Line colors in all panels correspond to the origins of the backward trajectories (blue: Fukuoka, light blue: Hiroshima, green: Okayama, purple: Kochi, orange: Kyoto, red: Gifu). Temporal discontinuities in (bd) are caused, as the backward tracing of a given air parcel is quitted when it reaches below the surface or outside of the model domain.

(a) Mixed-layer column water vapor anom.

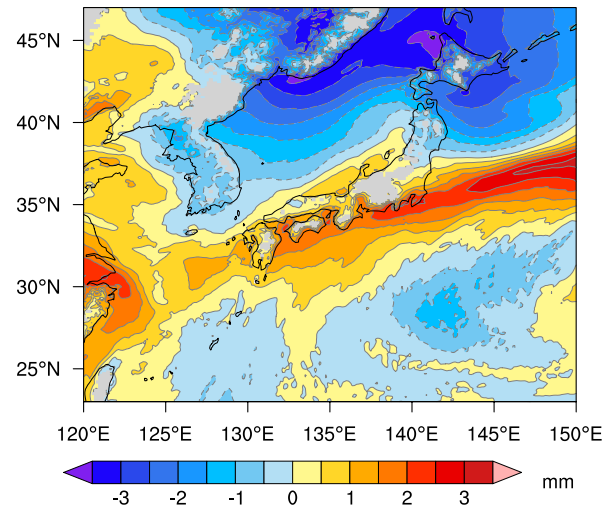

(b) Precipitable water anom.

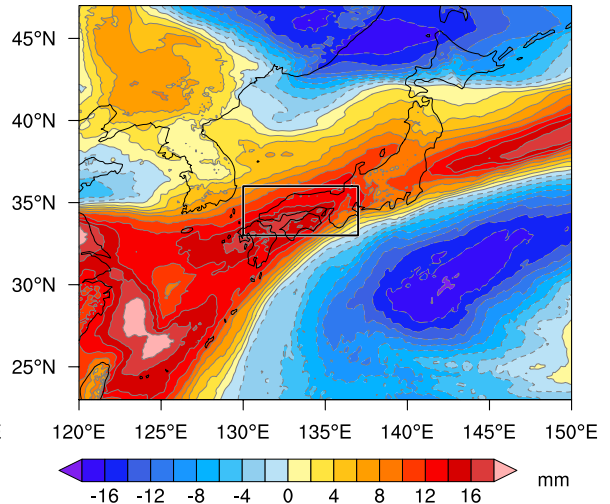

Fig. 6. Column water vapor anomaly (mm) integrated from the surface to (a) $925 \mathrm{hPa}$ and (b) top of the model (precipitable water), all averaged over the 48-hour peak period of the rainfall event. Black box $\left(33^{\circ} \mathrm{N}-36^{\circ} \mathrm{N}, 130^{\circ} \mathrm{E}-137^{\circ} \mathrm{E}\right)$ indicates the region for calculating area-averaged precipitable water anomaly over western Japan.

most of the starting grid points (Fig. 5d). This is because majority of the air parcels passed over the ocean with negative SST anomalies (Figs. $2 \mathrm{~b}$ and 5a). Nevertheless, as suggested in Section 3.2, positive SST anomalies account for $\sim 26 \%$ of the accumulated evaporation anomaly for the air parcels transported into Tokai region, including Gifu. The humidity term also contributed modestly to the western portion of the rainfall region (Fig. S4).

\section{Summary and discussion}

By means of high-resolution objective analysis and forecast data from JMA MSM, we have investigated anomalies in moisture transport and evaporation over the surrounding oceans during the peak period of the torrential rainfall event that occurred over 
western Japan in early July 2018. Consistent with Takemura et al. (2019) based on the JRA-55 global reanalysis with lower resolution, an enormous amount of moisture was supplied with the extreme southerlies (southwesterlies) from the Tropics toward the Baiu front stagnating over western Japan (Figs. 1a and 1c). Under the strong southerlies, evaporation was enhanced extensively over the surrounding oceans especially along the Kuroshio (Fig. 1c). Through our linear decomposition analysis applied to LHF anomaly, the enhanced evaporation over the south of Japan has been ascribed primarily to the increased wind speed over the southwest of western Japan (Figs. 2a and 3a) and to positive SST anomalies to its southeast (Figs. 2b and $3 b$ ). Our backward trajectory analysis has revealed that the enhanced moisture supply from the ocean south of western Japan due to wind-forced anomalous evaporation accounted for a considerable fraction of the column water vapor anomaly of the southerly moist airflow into the extreme rainfall region (Fig. 5). Our analysis has also revealed that the enhanced moisture flux into its eastern portion, including Tokai region, is contributed additionally by warm SST anomalies to the south (Fig. $5 \mathrm{~d})$. It is for future study to assess the role of the enhanced evaporation over the Sea of Japan under the influence of the developed Okhotsk High in the heavy rainfall.

The present study highlights the importance of enhanced evaporation from the Pacific and ECS for the intensified northward moisture transport into western Japan during the torrential rainfall event. It is not our intension, however, to claim that the evaporation was the primary factor of the extreme rainfall event. In fact, our decomposition analysis for the anomalous moisture flux has revealed that the enhanced flux was primary due to the intensified southerlies (Figs. 4a and 4b). We argue that the primary factor should be the intensification of the surface Bonin high (Fig. 2c) and enhanced convective activity over the southern ECS (Takemura et al. 2019; Shimpo et al. 2019). The anomalous evaporation should be regarded as one of the collateral factors for the extreme rainfall. This study is a case study focusing the particular event, in assessing the importance of oceanic evaporation. More comprehensive investigation is therefore needed to discuss general importance of oceanic evaporation in extreme rainfall events, which is likely to occur more frequently in future under the warmed climate.

\section{Acknowledgements}

The authors are grateful to the two anonymous reviewers for their constructive comments. This study is supported in part by the Japan Society for the Promotion of Science through KAKENHI Grants (JP18K19951, JP16H01844) and by the Japan Science and Technology Agency through Belmont Forum CRA "InterDec". Additional support is given by the Japanese Ministry of Education, Culture, Sports, Science and Technology through the "Integrated Research Program for Advancing Climate Models (TOUGOU program)". The JMA MSM data was provided by way of "Meteorological Research Consortium" and distributed by Research Institute for Sustainable Humanosphere, Kyoto University (http:// database.rish.kyoto-u.ac.jp/index-e.html).

Edited by: A. Manda

\section{Supplement}

Figure S1: Geographical locations of the regions referred to in this paper.

Figure S2: Meridional sections of potential temperature, specific humidity and relative humidity at $133^{\circ} \mathrm{E}$.

Figure S3: Comparison between surface LHF anomaly during the peak period of the heavy rainfall event and the corresponding anomaly derived as the sum of all 4 terms in Eq. (1).

Figure S4: Contributions from surface humidity anomaly and nonlinearity among anomalies to the accumulated anomalous evaporation along the trajectories as estimated on the basis of Eq. (1).

\section{References}

Fairall, C. W., E. F. Bradley, J. E. Hare, A. A. Grachev, and J. B. Edson, 2003: Bulk parameterization of air-sea fluxes: Updates and verification for the COARE algorithm. J. Climate, 16, 571-591.

Fujibe, F., 2015: Relationship between interannual variations of extreme hourly precipitation and air/sea-surface temperature in Japan. SOLA, 11, 5-9.

JMA, 2017: Joint WMO Technical Progress Report on the Global Data Processing and Forecasting System and Numerical Weather Prediction Research Activities for 2017, $62 \mathrm{pp}$. (Available online at http://www.jma.go.jp/jma/jma-eng/jmacenter/nwp/report/2017_Japan.pdf, accessed 30 March 2019).

Kobayashi, S., Y. Ota, Y. Harada, A. Ebita, M. Moriya, H. Onoda, K. Onogi, H. Kamahori, C. Kobayashi, H. Endo, K. Miyaoka, and K. Takahashi, 2015: The JRA-55 reanalysis: General specifications and basic characteristics. J. Meteor. Soc. Japan, 93, 5-48.

Kurihara, Y., T. Sakurai, and T. Kuragano, 2006: Daily sea-surface temperature over the global ocean constructed from satellite microwave, infrared and in-situ observations. JMA SokkoJiho Special Issue, 73, S1-S18 (in Japanese).

Manda, A., H. Nakamura, N. Asano, S. Iizuka, T. Miyama, Q. Moteki, M. K. Yoshioka, K. Nishii, and T. Miyasaka, 2014: Impacts of a warming marginal sea on torrential rainfall organized under the Asian summer monsoon. Sci. Rep., 4, 5741.

Shimpo, A., and co-authors, 2019: Primary factors behind the Heavy Rain Event of July 2018 and the subsequent heat wave in Japan. SOLA, 15A, 13-18, doi:10.2151/sola.15A003.

Takemura, K., S. Wakamatsu, H. Togawa, A. Shimpo, C. Kobayashi, S. Maeda, and H. Nakamura, 2019: Extreme moisture flux convergence over western Japan during the heavy rain event of July 2018. submitted to SOLA.

Tanimoto, Y., H. Nakamura, T. Kagimoto, and S. Yamane, 2003: An active role of extratropical sea surface temperature anomalies in determining anomalous turbulent heat flux. $J$. Geophys. Res., 108, C10, 3304.

Tsuguti, H., N. Seino, H. Kawase, Y. Imada, T. Nakaegawa, and I. Takayabu, 2019: Meteorological overview and mesoscale characteristics of the Heavy Rain Event of July 2018 in Japan. Landslides, 16, 363-371.

Manuscript received 30 March 2019, accepted 10 May 2019

SOLA: https://www.jstage.jst.go.jp/browse/sola/ 